\title{
Glucose-dependent arginine stimulation test for characterization of islet function: studies on reproducibility and priming effect of arginine
}

\author{
H. Larsson, B. Ahrén \\ Department of Medicine, Lund University, Malmö, Sweden
}

\begin{abstract}
Summary Quantitative determination of insulin secretion is of importance both clinically and in research. The optimal method has not been established, although several different methods have been used. We determined the reproducibility of islet function parameters obtained by the glucose-dependent arginine stimulation test, and also studied the priming effect of arginine on subsequent acute insulin responses. The test measures the acute insulin (AIR) and glucagon (AGR) responses to i. $\mathrm{v}$. arginine ( $5 \mathrm{~g}$ injected over $45 \mathrm{~s}$ ) at fasting glucose and glucose concentrations clamped at 14 and above $25 \mathrm{mmol} / \mathrm{l}$, as well as the glucose potentiation of insulin secretion $\left(\right.$ slope $\left._{\text {AIR }}\right)$ and the glucose inhibition of glucagon secretion $\left(\right.$ slope $\left._{\mathrm{AGR}}\right)$. When the test was performed twice in seven healthy women (mean \pm SD age $58.7 \pm 0.5$ years, BMI $27.6 \pm 5.5 \mathrm{~kg} / \mathrm{m}^{2}$ ), the AIRs to arginine had a within-subject coefficient of variation (CV) of $18.6 \%$ at fasting glucose, $18.7 \%$ at $14 \mathrm{mmol} / \mathrm{l}$ glucose and $16.3 \%$ at above $25 \mathrm{mmol} / \mathrm{l} \mathrm{glu}-$
\end{abstract}

cose. The CVs for AGR were 11.6, 14.9 and $8.9 \%$, respectively. The CV of the slope AIR was $24 \%$ and of the slope $_{\mathrm{AGR}} 17.2 \%$. The arginine priming study was performed in six healthy women (age $63.7 \pm 0.3$ years, BMI $\left.28.0 \pm 6.9 \mathrm{~kg} / \mathrm{m}^{2}\right)$. Saline or arginine $(5 \mathrm{~g})$ was injected at fasting glucose, followed by arginine $(5 \mathrm{~g})$ at $14 \mathrm{mmol} / \mathrm{l}$ glucose. There was no difference between the acute insulin or glucagon responses to arginine at $14 \mathrm{mmol} / \mathrm{l}$ glucose in the two conditions, suggesting that there is no priming effect of arginine on the subsequent acute insulin or glucagon responses. Therefore, this method is a good tool to determine insulin secretion as, apart from its good reproducibility, it also provides several important parameters of islet function. [Diabetologia (1998) 41: 772-777]

Keywords Islet function, arginine, insulin secretion, glucagon secretion, reproducibility, coefficient of variation, priming effect.
Characterization of insulin secretion is of interest to study the pathophysiology and development of Type

Received: 4 December 1997 and in final revised form: 13 February 1998

Corresponding author: Dr. Hillevi Larsson, Department of Medicine, Lund University, Malmö University Hospital, S20502 Malmö, Sweden

Abbreviations: AIR, acute insulin response to arginine; AGR, acute glucagon response to arginine; BG, blood glucose; CIGMA, continuous infusion of glucose with model assessment; $\mathrm{CI}$, confidence interval; CV, coefficient of variation; GLP-1, glucagon-like peptide-1; IVGTT, intravenous glucose tolerance test; Slope ${ }_{\mathrm{AIR}}$,glucose potentiation of insulin secretion; Slope $_{\text {AGR }}$, glucose inhibition of glucagon secretion.
II diabetes, and to evaluate new treatment of the disease. Therefore, reliable methods to estimate betacell function need to be established. The methods available for measuring insulin secretion include the hyperglycaemic clamp [1], the intravenous glucose tolerance test (IVGTT; [2]), the continuous infusion of glucose with model assessment (CIGMA, [3]) and the intravenous glucagon test $[4,5]$. However, no consensus has been reached as to which method is the best, neither in terms of characteristics nor reproducibility [6].

In studies of the role of insulin secretion in impaired glucose tolerance, we have previously used the method of glucose-dependent arginine stimulation [7-9]. This method was originally introduced by 
Ward et al. [10], and uses arginine injections to stimulate first-phase alpha- and beta-cell secretion both at fasting glucose and at clamped glucose concentrations of 14 and above $25 \mathrm{mmol} / \mathrm{l}$. This method enables estimations of the alpha- and beta-cell capacity, the beta-cell glucose sensitivity, and the glucose potentiation of insulin secretion and glucose inhibition of glucagon secretion to be made. Although this method gives multifaceted information on islet function, the bolus injection of arginine used does not cause a biphasic insulin release, as achieved by prolonged infusion of arginine [11]. The method has been fairly widely used during the last 15 years to determine insulin secretion in Type II diabetes [10] and in healthy subjects [8], after experimental insulin resistance [12, 13], and following administration of somatostatin [14] and the insulinotropic gut hormone, glucagonlike peptide-1 (GLP-1 [15]). However, the repeatability of this test has not been established.

Although it has been demonstrated in animal studies that one stimulation of insulin secretion might affect the response to a subsequent stimulation [16], it is not known whether arginine injection at fasting glucose level affects the subsequent measurements at 14 and above $25 \mathrm{mmol} / \mathrm{l}$ glucose levels in the glucose-dependent arginine stimulation test in humans. Therefore, this study aims to determine: i) the reproducibility of the glucose-dependent arginine injection test and ii) the priming effect of arginine on subsequent arginine stimulation of insulin and glucagon secretion under these conditions.

\section{Subjects and methods}

Subjects. We studied the reproducibility of the arginine stimulation test in seven middle-aged women (characteristics see Table 1 ). For the arginine priming study, 6 women participated (Table 1). Written informed consent was obtained from all subjects. The study was approved by the ethics committee of the Faculty of Medicine, Lund University. The women were all healthy and none used any medication known to affect glucose tolerance or insulin secretion. All studies were performed in the morning after an overnight fast with at least one week between visits. On a separate day, glucose tolerance was determined with a World Health Organisation (WHO) $75 \mathrm{~g}$ oral glucose tolerance test.

Reproducibility study. Insulin and glucagon secretion was determined with intravenous arginine stimulation at three blood glucose levels (fasting, 14 and $>25 \mathrm{mmol} / \mathrm{l}$ ), as introduced by Ward et al. [10]. The same test was performed twice. Intravenous catheters were inserted into antecubital veins in both arms. One arm was used for infusion of glucose, and the other arm for intermittent sampling. The sampling catheter was kept patent by slow infusion of $0.9 \%$ saline when not used. Baseline samples were taken at -5 and -2 min. A maximally stimulating dose of arginine hydrochloride $(5 \mathrm{~g})$ was then injected intravenously for $45 \mathrm{~s}$. Samples were taken at $+2,+3,+4$ and +5 min. A variable-rate $20 \%$ glucose infusion was then initiated to raise and maintain blood glucose at
Table 1. Clinical characteristics of the subjects in the two studies of reproducibility and arginine priming

\begin{tabular}{lcc}
\hline Characteristic & $\begin{array}{l}\text { Reproduci- } \\
\text { bility study } \\
(n=7)\end{array}$ & $\begin{array}{l}\text { Arginine } \\
\text { priming study } \\
(n=6)\end{array}$ \\
\hline Age (years) & $58.7 \pm 0.5^{\mathrm{a}}$ & $63.7 \pm 0.3$ \\
Body weight $(\mathrm{kg})$ & $72.2 \pm 14.3$ & $73.1 \pm 18.2$ \\
Body mass index $\left(\mathrm{kg} / \mathrm{m}^{2}\right)$ & $27.6 \pm 5.5$ & $28.0 \pm 6.9$ \\
Fasting blood glucose $(\mathrm{mmol} / \mathrm{l})$ & $4.7 \pm 0.6$ & $4.8 \pm 0.5$ \\
$2 \mathrm{~h}$ glucose $(\mathrm{mmol} / \mathrm{l})$ & $6.8 \pm 0.9$ & $6.6 \pm 0.7$ \\
$\mathrm{HbA}_{\mathrm{cc}}(\%)$ & $4.9 \pm 0.2$ & $4.9 \pm 0.3$ \\
\hline
\end{tabular}

${ }^{\text {a }}$ Data are shown as mean \pm SD

13-15 mmol/l. Blood glucose was determined every 5 min bedside, and the glucose infusion adjusted to reach the desired blood glucose level of $13-15 \mathrm{mmol} / \mathrm{l}$ in 20 to $25 \mathrm{~min}$. New baseline samples were taken, then arginine $(5 \mathrm{~g})$ was again injected and $+2,+3,+4$ and +5 -min samples taken. A 2.5-h resting period was allowed to avoid the well-known priming effect of hyperglycaemia [17, 18]. After the pause, baseline samples were again obtained. Then a high-speed $(900 \mathrm{ml} / \mathrm{h}) 20 \%$ glucose infusion during 25-30 min was used to raise blood glucose to above $25 \mathrm{mmol} / \mathrm{l}$, as determined bedside. At this blood glucose level, new baseline samples were taken, and arginine $(5 \mathrm{~g})$ injected, followed by final $+2,+3,+4$ and +5 -min samples.

Arginine priming study. To determine if the arginine injection at fasting glucose affects the result of the second arginine administration at $14 \mathrm{mmol} / \mathrm{l}$ glucose, we modified the study protocol as follows: after taking the baseline samples at -5 and $-2 \mathrm{~min}$, arginine $(5 \mathrm{~g})$ or saline $(0.9 \%)$ was injected, followed by samples at $+2,+3,+4$ and $+5 \mathrm{~min}$. Blood glucose was then raised to 13 to $15 \mathrm{mmol} / \mathrm{l}$ as described previously, after which new baseline samples were taken. Arginine was then injected and $+2,+3,+4$ and +5 -min samples obtained. This test was performed twice, once with injection of arginine and once with saline injection at the fasting glucose level. The two tests were performed in random order.

Analyses. Blood glucose concentration was determined bedside by the glucose dehydrogenase technique with an Accutrend (Boehringer Mannheim Scandinavia AB, Bromma, Sweden) during the arginine test. Serum insulin concentrations were analysed with a double-antibody radioimmunoassay technique. Guinea-pig anti-human insulin antibodies, human insulin standard and mono- ${ }^{125} \mathrm{I}-\mathrm{Ty}$-human insulin (Linco Res. Inc., St. Charles, Mo., USA) were used. The insulin antibody cross-reacts less than $0.2 \%$ with intact and des 31,32 proinsulin. Samples for analysis of glucagon were obtained in pre-chilled test tubes containing $0.084 \mathrm{ml}$ EDTA $(0.34 \mathrm{~mol} / \mathrm{l})$ and aprotinin (250 kallikrein inhibiting $\mathrm{u} / \mathrm{ml}$ blood (Bayer AG, Leverkusen, Germany). Analysis of glucagon concentration was performed with double-antibody RIA using guinea-pig antihuman glucagon antibodies specific for pancreatic glucagon, ${ }^{125} \mathrm{I}$-glucagon as tracer, and glucagon standard (Linco). Plasma glucose concentrations were analysed using the glucose oxidase method. Insulin, glucagon and glucose from the arginine studies were analysed in duplicate and concentrations were taken as the means of the duplicate samples.

Calculations and statistics. Data are presented as means \pm SEM, unless otherwise noted. The acute insulin response to arginine (AIR) was calculated as the mean of the +2 to + 5 min samples minus the prestimulus insulin concentration. 


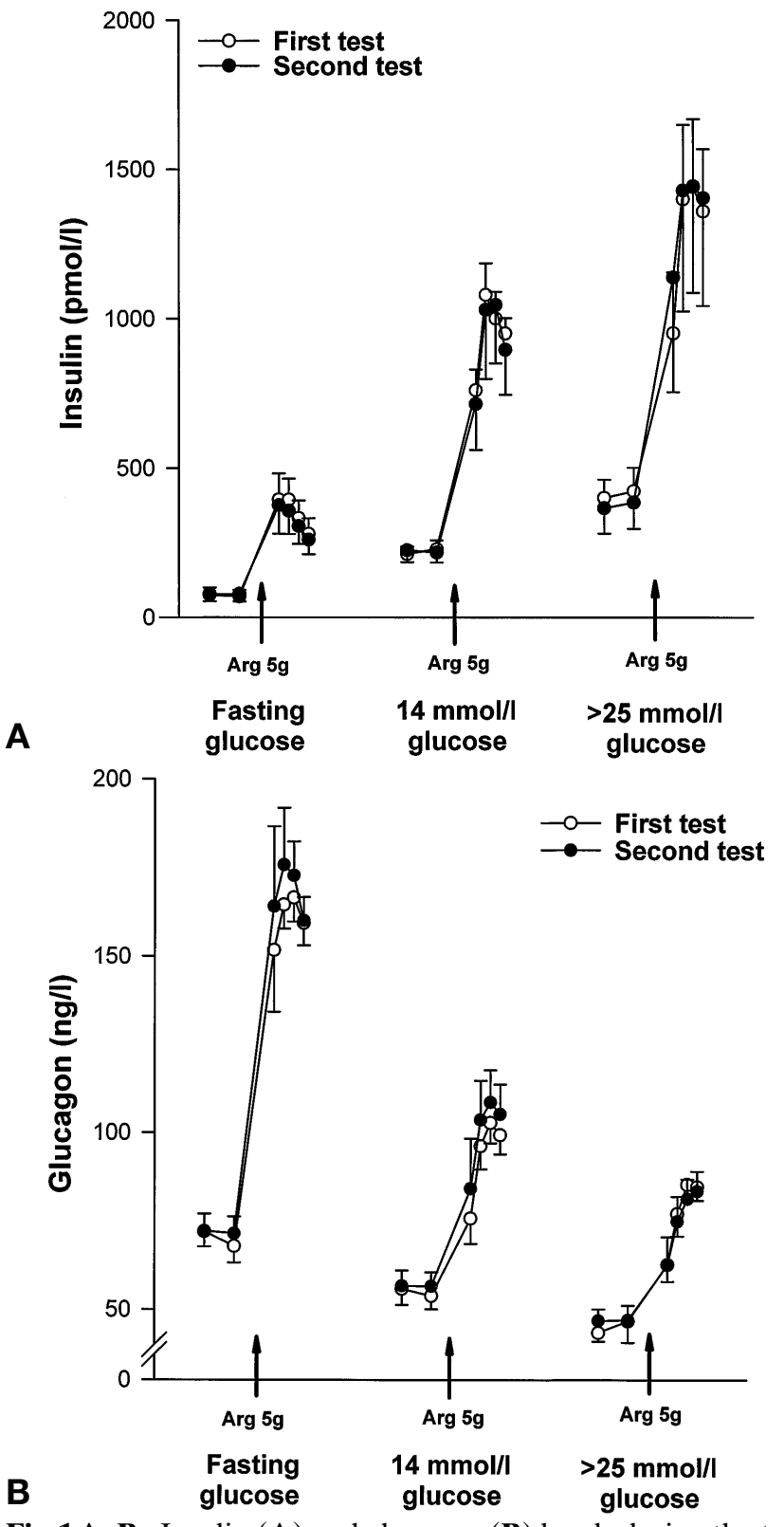

Fig.1 A, B. Insulin (A) and glucagon (B) levels during the two consecutive glucose-dependent arginine stimulation tests in seven healthy women. Data are shown as mean values, error bars denote SEM

The slope between AIR at fasting blood glucose and at blood glucose $14 \mathrm{mmol} / \mathrm{l}\left(\right.$ slope $_{\mathrm{AIR}}=\Delta \mathrm{AIR} / \Delta$ glucose $)$ was calculated as a measure of glucose potentiation of beta-cell secretion [19, 20]. The acute glucagon responses (AGR) and the slope $_{\mathrm{AGR}}$ (glucose inhibition of glucagon secretion) were calculated in the same manner.

Statistical analyses were performed with the SPSS for Windows system [21]. Within-subject coefficients of variation (CVs) were calculated as standard deviation divided by the mean value for each subject's two tests. Differences between the two test occasions were assessed with Student's $t$-test for related samples.

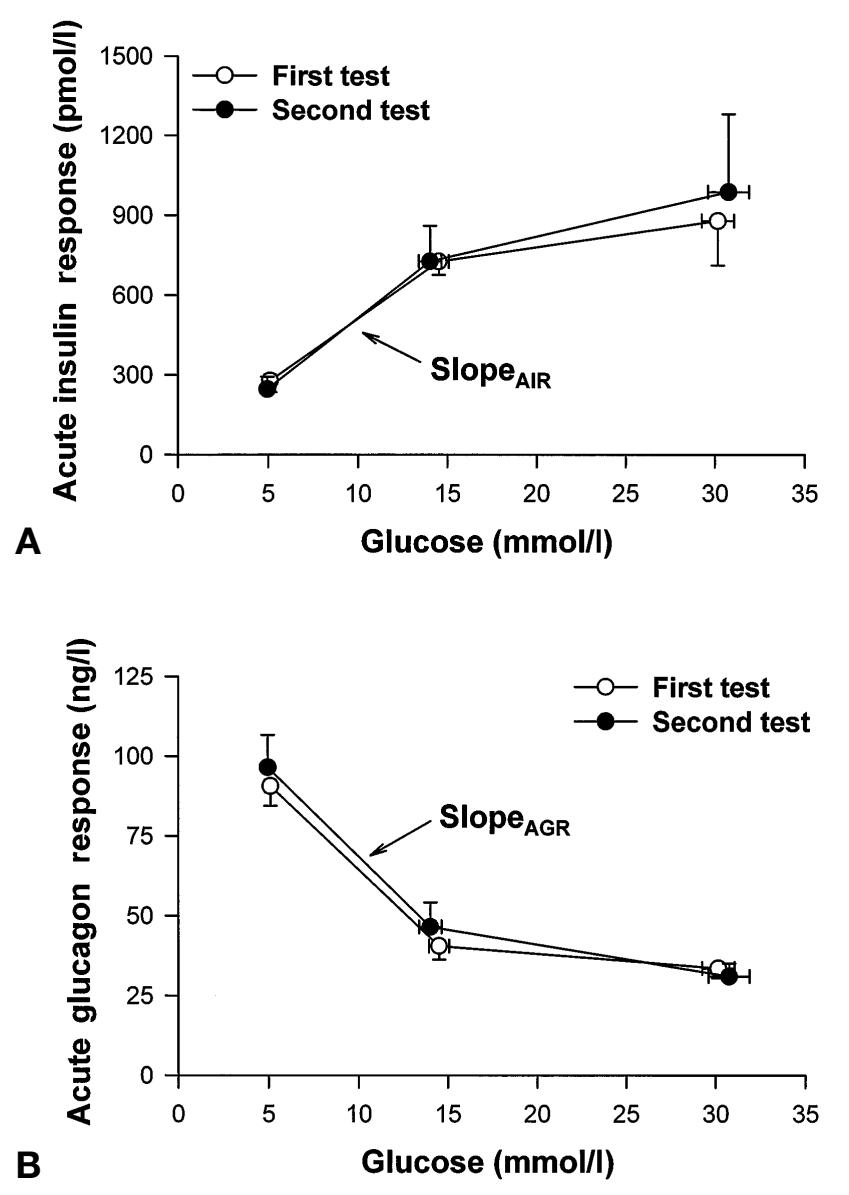

Fig. 2 A, B. Calculated acute insulin (A) and glucagon (B) responses during the two consecutive glucose-dependent arginine stimulation tests in seven healthy women. The figures also show the glucose potentiation of insulin secretion (slope $_{\mathrm{AIR}}$, A) and the glucose inhibition of glucagon secretion (slope AGR $_{\mathrm{AG}}$, B). Data are shown as mean values, error bars denote SEM

\section{Results}

Reproducibility study. The first study examined the reproducibility of the glucose-dependent arginine stimulation test by performing two consecutive tests in seven subjects. Figure 1 shows the insulin and glucagon concentrations during the two tests. It is seen that the two curves overlap, with no apparent differences between the two occasions. The calculated acute insulin and glucagon responses are depicted in Figure 2. There were no significant differences between the clamped glucose levels or any of the secretory variables when comparing the two tests (data not shown).

Coefficients of variation (CVs) were calculated for each individual pair of test values from the two occasions. Table 2 shows the mean values and the $95 \%$ confidence intervals of the CVs for the secretion variables. The mean variation of the different measures of insulin and glucagon secretion ranged from 9 to $27 \%$, with values of $18.6,18.7$ and $16.3 \%$ for the 
Table 2. Coefficients of variation for the secretory variables of the two consecutive glucose-dependent arginine stimulation tests in seven healthy women

\begin{tabular}{|c|c|c|}
\hline \multirow[t]{2}{*}{ Arginine test variable } & \multicolumn{2}{|l|}{$\mathrm{CV}$} \\
\hline & $\begin{array}{l}\text { Mean } \\
(\%)\end{array}$ & $\begin{array}{l}95 \% \text { CI for } \\
\text { mean }(\%)\end{array}$ \\
\hline Insulin at fasting BG (pmol/1) & 12.5 & $4.7-20.4$ \\
\hline Insulin at BG $14 \mathrm{mmol} / \mathrm{l}(\mathrm{pmol} / \mathrm{l})$ & 14.9 & $-0.8-30.5$ \\
\hline Insulin at $\mathrm{BG}>25 \mathrm{mmol} / \mathrm{l}(\mathrm{pmol} / \mathrm{l})$ & 27.3 & $13.4-41.1$ \\
\hline AIR at fasting BG (pmol/l) & 18.6 & $12.6-24.5$ \\
\hline AIR at BG $14 \mathrm{mmol} / \mathrm{l}(\mathrm{pmol} / \mathrm{l})$ & 18.7 & $6.7-30.7$ \\
\hline AIR at $\mathrm{BG}>25 \mathrm{mmol} / \mathrm{l}(\mathrm{pmol} / \mathrm{l})$ & 16.3 & $3.6-29.0$ \\
\hline Slope $_{\text {AIR }}(\mathrm{pmol}$ insulin/mmol glucose $)$ & 24.0 & $7.2-40.7$ \\
\hline Glucagon at fasting BG (ng/l) & 8.6 & $2.9-14.2$ \\
\hline Glucagon at BG $14 \mathrm{mmol} / \mathrm{l}(\mathrm{ng} / \mathrm{l})$ & 8.6 & $1.1-16.2$ \\
\hline Glucagon at $\mathrm{BG}>25 \mathrm{mmol} / \mathrm{l}(\mathrm{ng} / \mathrm{l})$ & 8.6 & $-2.9-20.1$ \\
\hline AGR at fasting BG (ng/l) & 11.6 & $5.1-18.2$ \\
\hline AGR at BG 14 mmol/l (ng/l) & 14.9 & $7.6-22.2$ \\
\hline AGR at $\mathrm{BG}>25 \mathrm{mmol} / \mathrm{l}(\mathrm{ng} / \mathrm{l})$ & 8.9 & $1.8-16.1$ \\
\hline Slope $_{\text {AGR }}$ (ng glucagon/mmol glucose $)$ & 17.2 & $2.6-31.7$ \\
\hline
\end{tabular}

acute insulin responses at fasting glucose, $14 \mathrm{mmol} / \mathrm{l}$ and above $25 \mathrm{mmol} / \mathrm{l}$ glucose, and 11.6, 14.9 and $8.9 \%$ for the acute glucagon responses.

In the calculations of the acute insulin and glucagon responses, the mean of the four post-challenge samples is used. Possibly, the method could benefit from reducing the number of post-stimulatory samples. Alternatively, fewer samples could cause an increase in the variation. We therefore calculated the acute insulin and glucagon responses using four different sample sets, and compared the CVs for each set (data not shown). The first sample set used all the +2 to +5 -min samples, the second set used the +2 and +4 -min values, the third set used the +3 and +5 -min samples, and the fourth sample set used the $+3,+4$ and +5 -min samples. Compared with using all the four samples (sample set 1), the second sample set (using the +2 and +4 -min samples) resulted in lower values for AIR at the 14 and above $25 \mathrm{mmol} / \mathrm{l}$ glucose levels, while sample sets 3 and 4 resulted in higher values for AIR at these glucose levels. This is due to the fact that the peak response is delayed at the higher glucose levels (Fig. 1A). For the acute glucagon responses, a similar pattern was seen. Despite these differences in the values for AIRs and AGRs, the mean CVs obtained by the different sample sets were similar.

Arginine priming study. The second study examined whether the arginine injection at fasting glucose affected the subsequent response to arginine at $14 \mathrm{mmol} / \mathrm{l}$ glucose. Insulin and glucagon levels did not change after the saline injection at the fasting level, whereas after the arginine injection the expected rapid but transient increase in insulin and glucagon levels were seen (Fig. 3). After raising blood glucose to $14 \mathrm{mmol} / \mathrm{l}$, the insulin and glucagon responses to

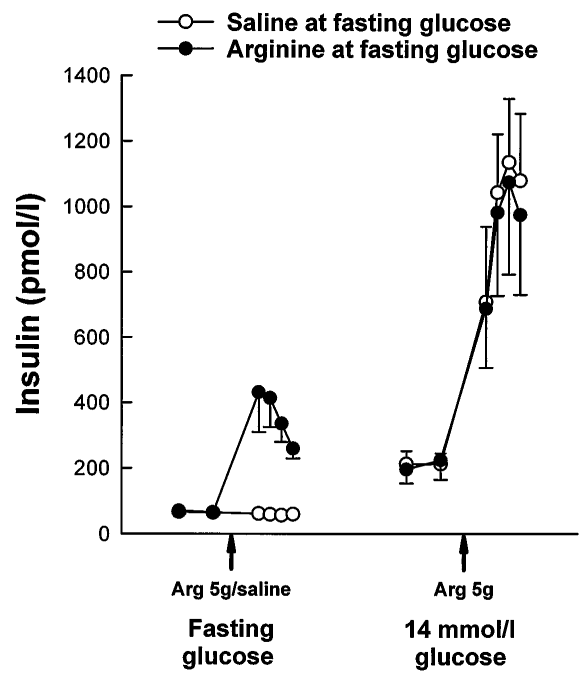

A

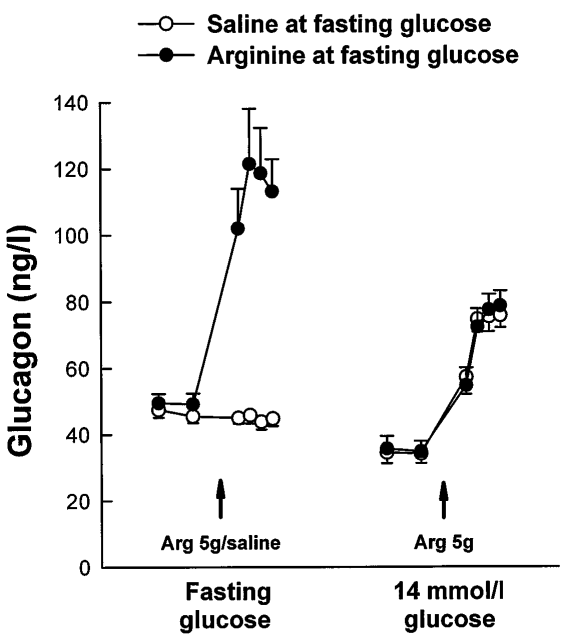

Fig. 3 A, B. Insulin (A) and glucagon (B) levels after arginine or saline injection at the fasting glucose level followed by arginine injection at the $14 \mathrm{mmol} / \mathrm{l}$ glucose level in 6 healthy women. Data are shown as mean values, error bars denote SEM

the arginine injection were similar regardless of whether saline or arginine had been given at the fasting level (Fig. 3).

\section{Discussion}

The glucose-dependent arginine stimulation test was introduced by Ward et al. [10], and has been used for studies of islet function for nearly two decades $[8,10$, $12-15,20]$. It is a method which gives thorough information on islet function, because it measures both basal and maximal alpha- and beta-cell secretion along with the glucose potentiation of insulin secretion and the glucose inhibition of glucagon secretion. However, its reproducibility has not been verified previously. Since it is important to consider the possible variation of islet function when evaluating the results of the test, we studied the reproducibility of pa- 
rameters of islet function obtained after arginine injection at three different glucose levels.

We found that the mean coefficients of variation for the different parameters of islet function ranged from around 10 to $20 \%$. This variation could be due to several reasons. First, there is certainly a biological variation in the alpha- and beta-cell function. For example, it is known that fasting insulin varies from day to day with a mean CV of around $20 \%$ [5, 22]. Second, although kept at a minimum when used in experienced hands, the study method itself can produce some variation, like differences in the glucose levels achieved during the clamping at 14 and above $25 \mathrm{mmol} / \mathrm{l}$, the speed of the arginine injection and the timing of the blood samples. Third, there is a variation in the radioimmunoassays for insulin and glucagon. In our laboratory, the intra- and inter-individual CV for the insulin assay is less than $3 \%$ and for the glucagon assay less than $5 \%$. Therefore, our finding of CVs between 10 and $20 \%$ for the various secretory paramters of the test is very good in this context.

We also examined the sampling protocol to see if it could be adjusted using fewer post-stimulatory samples, to simplify the method. There were no clear differences in the mean CVs obtained with the protocols using fewer samples compared with the full protocol. However, it was noted that the $95 \%$ CIs were lower using all the +2 to +5 min samples to calculate the acute insulin responses. Furthermore, the reduced sample sets resulted in different values for the calculated acute insulin and glucagon responses at the 14 and above $25 \mathrm{mmol} / \mathrm{l}$ glucose levels. This could be disadvantageous when comparing results between different studies. Therefore, we conclude that there is no benefit in reducing the number of post-stimulatory samples from the originally suggested four samples.

The variation found in this study is comparable with that shown for other methods used to estimate beta-cell function. For example, for the IVGTT the mean coefficients of variation of first-phase insulin secretion have ranged between 20 and $30 \%$ [2, 23-25]. There have, though, been some studies that have demonstrated a considerably lower variability, around 4 to $9 \%[26,27]$. Another measure of betacell function is the CIGMA, which showed a mean CV of $19 \%$ for the beta-cell function estimate [3]. Insulin secretion after injection of glucagon also demonstrated a similar mean CV of $24.8 \%$ [5]. While the mean CVs for insulin secretion were low in this study, the $95 \%$ CIs were rather wide due to the small study group. Since the presently studied method thus is equivalent in terms of $\mathrm{CV}$, but superior in terms of allowing conclusions on a multitude of parameters of insulin and glucagon secretion, we consider this method to be advantageous for characterizing islet function in humans. However, since the method is labour-intensive and time-consuming, it is not the ideal test in epidemiological studies but should be reserved for more detailed evaluation of various aspects of beta-cell function. A limitation of the present study is that it was performed in healthy subjects and not in individuals with type II diabetes.

It has previously been demonstrated that arginine can exert a time-dependent inhibitory effect on insulin secretion. Thus, in isolated rat pancreas, arginine generated a potent inhibition of insulin secretion, which lasted at least $2 \mathrm{~h}$ [16]. Furthermore, a study in humans reported that priming with an arginine infusion or injection reduced the insulin responses to subsequent stimulation [28]. Therefore, in the method by Ward et al., the arginine injection at fasting glucose might affect the following measurements at 14 and above $25 \mathrm{mmol} / \mathrm{l}$ glucose. To resolve this question, we performed control experiments with saline injections at fasting glucose. We found that there was no difference between the acute insulin responses at $14 \mathrm{mmol} / \mathrm{l}$ glucose after arginine or saline injections at the fasting glucose level. Therefore, we conclude that using this protocol, there is no inhibitory effect of arginine on the subsequent acute insulin responses. Neither was there an effect on the glucagon responses, which was expected, since the previous studies have demonstrated no inhibitory effect of arginine on glucagon secretion [28].

In summary, we have shown that the method of glucose-dependent arginine stimulation gives a well reproducible measurement of alpha- and beta-cell secretion, with coefficients of variation ranging from 10 to $20 \%$. Moreover, there was no indication that the arginine injection at fasting glucose could modify the subsequent insulin and glucagon responses to arginine at $14 \mathrm{mmol} / \mathrm{l}$ glucose. Therefore, we conclude that this method is a good tool to determine alphaand beta-cell secretion as, apart from its good reproducibility, it also provides several important parameters of islet function.

Acknowledgements. The authors are grateful to Lilian Bengtsson, Ulrika Gustavsson, Eva Holmström, Gertrud Jensen and Margaretha Persson for expert technical assistance. The study was supported by the Swedish Medical Research Council (grant no 14X-6834), Ernhold Lundström, Albert Påhlsson and Novo Nordisk Foundations, the Swedish Diabetes Association, the Malmö University Hospital and the Faculty of Medicine, Lund University.

\section{References}

1. DeFronzo RA, Tobin JD, Andres R (1979) Glucose clamp technique: a method for quantifying insulin secretion and resistance. Am J Physiol 237:E214-E223

2. Bardet S, Pasqual C, Maugendre D, Remy JP, Charbonnel B, Sai P (1989) Inter and intra individual variability of acute insulin response during intravenous glucose tolerance tests. Diabetes Metab 15: 224-232

3. Hosker JP, Matthews DR, Rudenski AS et al. (1985) Continuous infusion of glucose with model assessment: mea- 
surement of insulin resistance and $\beta$-cell function in man. Diabetologia 28: 401-411

4. Scheen AJ, Castillo MJ, Lefebvre PJ (1996) Assessment of residual insulin secretion in diabetic patients using the intravenous glucagon stimulatory test: methodological aspects and clinical applications. Diabetes Metab 22: 397-406

5. Gjessing HJ, Damsgaard EM, Matzen LE, Frøland A, Faber OK (1987) Reproducibility of $\beta$-cell function estimates in non-insulin-dependent diabetes mellitus. Diabetes Care 10: $558-562$

6. Groop LC, Widén E, Ferrannini E (1993) Insulin resistance and insulin deficiency in the pathogenesis of type II (noninsulin-dependent) diabetes mellitus: errors of metabolism or of methods? Diabetologia 36: 1326-1331

7. Larsson H, Berglund G, Ahrén B (1995) Glucose modulation of insulin and glucagon secretion is altered in impaired glucose tolerance. J Clin Endocrinol Metab 80: 1778-1782

8. Larsson H, Ahrén B (1996) Failure to adequately adapt reduced insulin sensitivity with increased insulin secretion in women with impaired glucose tolerance. Diabetologia 39: 1099-1107

9. Larsson H, Ahrén B (1996) Islet dysfunction in obese women with impaired glucose tolerance. Metabolism 45: 502-509

10. Ward WK, Bolgiano DC, McKnight B, Halter JB, Porte D, Jr (1984) Diminished B cell secretory capacity in patients with noninsulin-dependent diabetes mellitus. J Clin Invest 74: $1318-1328$

11. Van Haeften TW, Van Maarschalkerweerd WWA, Gerich JE, Van Der Veen EA (1991) Decreased insulin secretory capacity and normal pancreatic beta-cell glucose sensitivity in non-obese patients with NIDDM. Eur J Clin Invest 21: $168-174$

12. Beard JC, Halter JB, Best JD, Pfeifer MA, Porte D, Jr (1984) Dexamethasone-induced insulin resistance enhances B cell responsiveness to glucose level in normal man. Am J Physiol 247:E592-E596

13. Kahn SE, Beard JC, Schwartz MW et al. (1989) Increased $\beta$-cell secretory capacity as mechanism for islet adaptation to nicotinic acid-induced insulin resistance. Diabetes 38: $562-568$

14. Kahn SE, Klaff LJ, Schwartz MW et al. (1990) Treatment with a somatostatin analog decreases pancreatic B-cell and whole body sensitivity to glucose. J Clin Endocrinol Metab 71: 994-1002

15. Ahrén B, Larsson H, Holst JJ (1997) Effects of glucagonlike peptide-1 on islet function and insulin sensitivity in noninsulin-dependent diabetes mellitus. J Clin Endocrinol Metab 82: 473-478

16. Nesher R, Eylon L, Segal N, Cerasi E (1989) $\beta$-cell memory to insulin secretagogues:characterization of the time-dependent inhibitory control system in the isolated rat pancreas. Endocrinology 124: 142-148

17. Cerasi E (1975) Potentiation of insulin release by glucose in man. Acta Endocrinol 79: 511-534

18. Grill V (1981) Time and dose dependencies for priming effect of glucose on insulin. Am J Physiol 240:E24-E31

19. Halter JB, Graf RJ, Porte D, Jr (1979) Potentiation of insulin secretory responses by plasma glucose levels in man: evidence that hyperglycaemia in diabetes compensates for impaired glucose potentiation. J Clin Endocrinol Metab 48: 946-954

20. Porte D, Jr (1991) Banting lecture 1990. $\beta$-cells in type II diabetes mellitus. Diabetes 40: 166-180

21. Norusis MJ (1992) SPSS for Windows: Base System User's Guide, Release 5.0. SPSS, Chicago

22. Mooy JM, Grootenhuis PA, de Vries H et al. (1996) Intraindividual variation of glucose, specific insulin and proinsulin concentrations measured by two oral glucose tolerance tests in a general Caucasian population: the Hoorn Study. Diabetologia 39: 298-305

23. Smith CP, Tarn AC, Thomas JM et al. (1988) Between and within subject variation of the first phase insulin response to intravenous glucose. Diabetologia 31: 123-125

24. Abbate SL, Fujimoto WY, Brunzell JD, Kahn SE (1993) Effect of heparin on insulin-glucose interactions measured by the minimal model technique: implications for reproducibility using this model. Metabolism 42: 353-357

25. Steil GM, Murray J, Bergman RN, Buchanan TA (1994) Repeatability of insulin sensitivity and glucose effectiveness from the minimal model. Implications for study design. Diabetes 43: 1365-1371

26. Rayman G, Clark P, Schneider AE, Hales CN (1990) The first phase insulin response to intravenous glucose is highly reproducible. Diabetologia 33: 631-634

27. McNair PD, Colman PG, Alford FP, Harrison LC (1995) Reproducibility of the first-phase insulin response to intravenous glucose is not improved by retrograde cannulation and arterialization or the use of a lower glucose dose. Diabetes Care 18: 1168-1173

28. Efendic S, Lins PE, Cerasi E (1979) Potentiation and inhibition of insulin release in man following priming with glucose and with arginine - effect of somatostatin. Acta Endocrinol 90: 259-271 